\title{
Human Error in Medication Administration Process
}

\author{
Amr Zyoud
}

Ph.D Student, Universiti Utara Malaysia, amr.zyoud@gmail.com

Nor Azimah Chew Abdullah

Dr. PH, Universiti Utara Malaysia, norazimah@uum.edu.my

Doi:10.5901/mjss.2016.v7n3s1p403

\section{Abstract}

\begin{abstract}
Context: Medication administration errors is continuous problem in hospitals and occur too frequently, error is unavoidable human action, since medication treatment is a risky procedure that deal with human live therefore error in this process can lead to dangerous consequences on patient well-being, traditionally nurses were blamed for those errors and considered as malpractice action since medication treatment is manly performed by nurses. Objectives: The current study examines the conditions that influence medication error in the perspective systemic approach. Methods: reviewing medication error contributing conditions topic is outlined, exploiting different perspective of how error occurs in medication process. Results and conclusion: the present study concluded that system approach permit a comprehensive set of contributing conditions underlying medication error to be recognize and addressed, rather than just adopt individual centered approach, Future studies should examine underlying conditions, in the perception of work practice environment conditions, team work conditions, task related conditions and individual conditions.
\end{abstract}

Keywords: Medication errors, systemic cantered approach, individual factors, and systemic factors.

\section{Introduction}

In the healthcare industry, the process of medication treatment is essential phase in process of providing medical services; in fact, it is the most medical practice in hospitals (Armitage \& Knapman, 2003; Tang, Sheu, Yu, Wei, \& Chen, 2007). Indeed, the amplified numbers of patients and the rising numbers of drugs applied in medical practice has boosted the possibility of accidents during this process (Anderson \& Webster, 2001). As a result, the rising numbers of medication error will increase the strain on healthcare authority to continue improving their safety procedure to keep the medication error in the lowest levels.

Nevertheless, in the healthcare industry most of errors were attributed to individual malpractice and negligent of professional behavior without taking into consideration other factors that influence the operation system that they work in (Reason J. ., 1995). As a result, most of initiative that dealt with those errors has persistently reacted in an individual and punitive procedures (Dean, B., Schachter, M., Vincent, C., \& Barber, N, 2002; Heimbeck, Frese, Sonnentag, \& Keith, 2003; Keith \& Frese, 2005). Nevertheless, despite of those strategies, the pace of medication errors rate has been elevated in the recent years (Kelly W. , 2004). Therefore, the aim of this article is to discuss the prospective of medication error in the healthcare industry, exploiting different approaches that analysis error process in the healthcare system, comparing their perspectives and noting common criticism to determine the appropriate approach to deal with medication error, and finally presenting conclusions, implications, and future research directions.

\section{The Nature of Human Error}

Medication error is described as any error or a mistake in the stages of performing medication treatment to the patient (Chang \& Mark, 2011). Further, the tendency for error is intrinsic to human actions, an error in performance originated from human cognitive capability or psychomotor ability, leading to unsafe and inaccuracy execution of the medication process (Reason, 1990). As a human we commute errors regardless any safety measure, in fact, most of the time human don't desired doing those errors however errors will eventually occur (Reason, 1995). Further, in a complex workplace like providing healthcare services to human, the chance of having those errors in a wide scale is highly possible (Leape, 1994).

Healthcare authorities used individual centered approach to deal with medication error (Reason , 2000), 
accordingly, incorporating a subjective point view of individual liability as a replacement for a system failure to initiate strategies aimed to reduce medication error in the healthcare.

\subsection{Individual approach vs. System approach}

Error is unavoidable element of human actions, yet the consideration of error as an indication of malpractice behavior lead to perceive medication errors as personal failure, therefore healthcare professionals would act in discreet manner regarding any errors, because of the fear of staining their reputation which limited any attempt to element those errors (Anderson \& Webster, 2001). Medication errors can be analyzed in two pathways; the individual approach and the system approach, each approach utilize varied viewpoint of how error occur (Reason, 2000).

The individual approach highlights the personal hazardous action and behaviors that breach the professional standard measures (Reason, 2000). In addition, the individual approach is commonly domain tradition adopted in the healthcare, as a result errors will occur mostly because of atypical behaviors like absentmindedness, lack of attentiveness, poor motivation, carelessness, and unreliability (Reason, 1990). Nevertheless, in reality this approach has severe limitation, although some errors could be are caused by unprofessional performance, studies estimates that almost $90 \%$ of medical error are attributed to the system that healthcare professional work in (Marx, 1997).

Indeed, the error itself is an outcome; the real cause of error is human behavior $(\mathrm{DoH}, 2000)$. Further, human behaviors are customized under the system that they operate in (Reason, 1995). Consequently, the system that they work in is accountable for errors, system operators are the sharp end of the system and regularly they are the ones that identify those errors (Anderson \& Webster, 2001). Yet, when they are considered accountability of those errors, this will mask the system role in that contribute to error occurrence and those errors will occur again (Reason, 1990).

Alternatively, by adopting the system approach the human error is viewed as outcome rather than a source (Reason, 2000). As a result, the main concern is to investigate the reasons that caused errors to occur, rather than who are blamed. Consequently, it's significant to recognize circumstances that caused professionals to act in unsafe manner. Indeed, defect spots in the system structure and mechanisms, those defect spots in the operating system allow errors to occur (Reason, 1990). Hence, by recognizing system defect spot and redesigning the system process to eradicate the influence of those factors.

\section{The theory of Human Error (Accident Causation Model)}

The nature of human error is an extensive concept; James Reason has defined human error as "all occasions in which a planned sequence of mental or physical activity fails to achieve its intended outcome". (Reason, 1990, p. 9). Reason (1995) suggested that healthcare is a complicated and complex environment were several factors interrelated in various mechanizes, hence with various complex factors interrelate; the possibility of unanticipated event (e.g., errors) will increase (Reason, 2000). Errors can be classified as active and latent failures. First, active failures are hazardous actions executed by professionals engaging in the treatment process; those failures can be in different forms: slips, lapses, malfunction, and procedural breaches (Reason, 1990).

Furthermore, latent condition is fault in the system design or operation (Reason, 1990). Those conditions are not obvious; however they can trigger active conditions to cause a breach the professional practices of the medication process. Further, active conditions involve system operator "sharp end" in direct contact with the patient while latent conditions involve the organizational design and management method of the organization. Consequently, at person level; professional incorrect decision causes error, hence at the executive level; the board decision can generate conditions that facilitate errors (Zhang, Patel, \& Johnson, 2002).

\subsection{Factors affecting medication error}

The unsafe actions are examination as result, not as cause of the error (Reason, 2000). Furthermore, actions leading to errors are powered by conditions that vary from individual conditions (active conditions) like exhaustion, disturbance in rational judgment. Furthermore, other conditions go beyond the individual conditions to systematic conditions (latent conditions) which bond with active failures to create errors that turn out to be intrinsic in the system operational process (Reason, 2000; Vincent, Taylor-Adams, \& Stanhope, 1998). Systemic conditions can be classified to; Work environment conditions, team work conditions, task related conditions (Dean et al., 2002; Reason, 1995; Reason, 2000).

First, positive work environment can aid professional nursing practice, develop the excellence of medical care, and leading to more safety practice and less medication error (Aiken et al., 2008; Aiken et al., 2010; Flynn et al., 2010; Flynn 
et al., 2012; Tervo-Heikkinen et al., 2008; Thomas-Hawkins et al., 2008). Secondly, team work and affairs between medical team is connected with elevated quality of care for patients (Gittell, et al., 2000). Medication treatment process is multipart process were the failures of accurate communication is significant causal factor in medication error (Bates \& Gawande, 2003; Phillips et al., 2001; Taxis \& Barber, 2003).

Thirdly, medication treatment assignment is a complicated in nature; as a result the task related conditions can affect the way the process is performed (Reason, 1995). Indeed, medication treatment process supportive feature that is provided to medical team can affect the method of performing the task in more effective and efficient manner, (e.g. electronic prescription system, supportive devices in the administrating medication to the patients). Finally individual conditions coupled with system conditions influence the performance of medication treatment. However, most of prior researches focus mainly on malpractice factors like negligence and irresponsibility (Brady et al., 2009; Reason, 1995). Nevertheless, other individual factors can play a role in medication error occurrences (Armitage \& Knapman, 2003; O'Shea, 1999).

Studies have reported that factors like training, mathematical ability of medication calculation process and the knowledge of the medication can affect the occurrence of medication error (Armitage \& Knapman, 2003; Brady, et al., 2009; Mrayyan et al., 2007; O'Shea, 1999; Wright, 2010).

Future studies should inspect the error producing conditions, in the perspective of work practice environment conditions, team work conditions, task related conditions and individual conditions. This new approach will seek to investigate the interaction between those conditions to focuses on to recognize the variables that facilitate the incidence of medication error. Therefore, the present study has proposed a theatrical framework that encompasses set of conditions that can produce medication error by adopting determents derivative from theory of human error (Reason, 1990), and the theoretical frame was customized to be effectively applied in the perspective of healthcare sittings. Moreover, previous studies attempted to extend human error model to incorporate all factors that can play a role in the mechanism of medication error process (Chang \& Mark, 2009; Chang \& Mark, 2011; Dean et al., 2002; Tervo-Heikkinen et al., 2008). Further, Figure1 demonstrate the proposed framework.

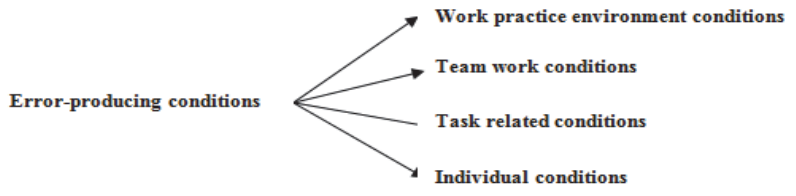

Figure 1: Proposed Research Model

\section{Conclusion}

Medication errors are human actions, it essential to comprehend the mechanism that errors develop and conditions that influence error occurrence to develop intervention that deal with this phenomena. The present study shed light on the way error is perceived in healthcare sittings and focused on the important of system approach to investigate conditions that influence medication error rather than the traditional individual centered approach adopted in healthcare.

\section{References}

Aiken, L. H., Cimiotti, J., Sloane, D., Smith, H., Flynn, L., \& Neff, D. (2010). Implications of the California nurse staffing mandate for other states. Health Services Research, 45(4), 904-921.

Aiken, L. H., Clarke, S. P., Sloane, D. M., Lake, E. T., \& Cheney, T. (2008). Effects of hospital care environment on patient mortality and nurse outcomes. Journal of Nursing Administration, 18(5), 223-229.

Anderson, D. J., \& Webster, C. S. (2001). A systems approach to the reduction of medication error on the hospital ward. Journal of advanced nursing, 35(1), 34-41.

Armitage, G., \& Knapman, H. . (2003). Adverse events in drug administration: a literature review. Journal of nursing management, 11(2), $130-140$.

Barker, K. N., Flynn, E. A., Pepper, G. A., Bates, D. W., \& Mikeal, R. L. (2002). Medication errors observed in 36 health care facilities. Archives of Internal Medicine, 162(16), 1897-1903.

Bates, D., \& Gawande, A. (2003). Improving safety with information technology. New England Journal of Medicine, 348(25), $2526-2534$.

Brady, A., Redmond, R., Curtis, E., Fleming, S., Keenan, P., MALONE, A., \& Sheerin, F. (2009). Adverse events in health care: a 
literature review. Journal of nursing management, 17(2), 155-164.

Chang, Y., \& Mark, B. (2009). Antecedents of severe and nonsevere medication errors. Journal of Nursing Scholarship, 41(1), 70-78.

Chang, Y., \& Mark, B. . (2011). Moderating Effects of Learning Climate on the Impact of RN Staffing on Medication Errors. Nursing research, 60(1), 32-39.

Dean, B., Schachter, M., Vincent, C., \& Barber, N. (2002). Causes of prescribing errors in hospital inpatients: A prospective study. Lancet, 359(9315), 1373-1378.

DoH. (2000). An Organisation with a Memory, Report of an Expert Group on Learning from Adverse Events in the NH. London: Department of Health.

Donabedian, A. (1988). The quality of care: How can it be assessed? JAMA, 260(12), 1743-1748.

Flynn, L., Liang, Y., Dickson, G. L., \& Aiken, L. H. (2010). Effects of nursing practice environments on quality outcomes in nursing homes. Journal of the American Geriatric Association, 2401-2406.

Flynn, L., Liang, Y., Dickson, G. L., Xie, M., \& Suh, D. C. (2012). Nurses' practice environments, error interception practices, and inpatient medication errors. Journal of Nursing Scholarship, 44(2), 180-186.

Fuqua, R. A., \& Stevens, K. R. (1988). What we know about medication errors: a literature review. Journal of Nursing Care Quality, 3(1), 2-17.

Gittell, J. H., Fairfield, K. M., Bierbaum, B., Head, W., Jackson, R., Kelly, M., . . Zuckerman, J. (2000). Impact of relational coordination on quality of care, postoperative pain and functioning, and length of stay: a nine-hospital study of surgical patients. Medical care, 38(8), 807-819.

Hand, K., \& Barber, N. (2000). Nurses' attitudes and beliefs about medication errors in a UK hospital. International Journal of Pharmacy Practice, 8(2), 128-134.

Heimbeck, D., Frese, M., Sonnentag, S., \& Keith, N. (2003). Integrating errors into the training process: The function of error management instructions and the role of goal orientation. Personnel Psychology, 56(2), 333-361.

Keill, P., \& Johnson, T. (1993). Shifting gears: improving delivery of medications. Journal of Nursing Care Quality, 7(2), 24-33.

Keith, N., \& Frese, M. (2005). Self-regulation in error management training: Emotion control and metacognition as mediators of performance effects. Journal of Applied Psychology, 90(4), 677-691.

Kelishadi, R., \& Mousavinasab, F. (2012). Rational use of medicine in the pediatric age group: A summary on the role of clinical pharmacists. Journal of Research in Pharmacy Practice, 1(1), 10-13.

Kelly, L., \& Vincent, D. (2011). The dimensions of nursing surveillance: a concept analysis. Journal of advanced nursing, 67(3), 652-661.

Kelly, W. (2004). Medication errors: lessons learned and actions needed. Professional Safety, 49, 35-41.

Leape, L. L. (1994). Error in medicine. JAMA-Journal of the American Medical Association-US Edition, 272(23), 1851-1856.

Lucero, R., Lake, E., \& Aiken, L. . (2009). Variations in nursing care quality across hospitals. Journal of advanced nursing, 65(11), 22992310.

Marx, D. (1997). Discipline: The role of rule violations. Ground Effects, 2, 1-4.

McBride-Henry, K., \& Foureur, M. . (2006). Medication administration errors: understanding the issues. Australian Journal of Advanced Nursing, 23(3), 33-41.

Mitchell, P. H., Ferketich, S., \& Jennings, B. M. (1998). Quality health outcomes model. Journal of Nursing Scholarship, 30(1), 43-46.

MPIC, M. o. (2007). Jordan National Competitiveness Report 2007. Ministry of Planning and International Cooperation Jordan.

Mrayyan, M., Shishani, K., \& Al-Faouri, I. (2007). Rate, causes and reporting of medication errors in Jordan: nurses' perspectives. Journal of nursing management, 15(6), 659-670.

O'Shea, E. . (1999). Factors contributing to medication errors: a literature review. Journal of clinical nursing, 8(5), 496-504.

Phillips, J., Beam, S., Brinker, A., Holquist, C., Honig, P., Lee, L. Y., \& Pamer, C. (2001). Retrospective analysis of mortalities associated with medication errors. American Journal of Health-System Pharmacy, 58(19), 1835-1841.

Reason, J. (1990). Human error. Cambridge, UK: Cambridge university press.

Reason, J. (1995). Understanding adverse events: human factors. Quality in Health Care, 4(2), 80-89.

Sanghera, I. S., Franklin, B. D., \& Dhillon, S. . (2007). The attitudes and beliefs of healthcare professionals on the causes and reporting of medication errors in a UK Intensive care unit. Anaesthesia, 62(1), 53-61.

Tang, F. I., Sheu, S. J., Yu, S., Wei, I. L., \& Chen, C. H. (2007). Nurses relate the contributing factors involved in medication errors. Journal of clinical nursing, 16(3), 447-457.

Taxis, K., \& Barber, N. . (2003a). Causes of intravenous medication errors: an ethnographic study. Quality and Safety in Health Care, 12(5), 343-347.

Tervo-Heikkinen, T., Partanen, P., Aalto, P., \& Vehviläinen-Julkunen, K. . (2008). Nurses' work environment and nursing outcomes: A survey study among Finnish university hospital registered nurses. International journal of nursing practice, 14(5), 357-365.

Thomas-Hawkins, C., F. L., \& Clarke, S. P. (2008). Relationships between registered nurse staffing, processes of nursing care, and nurse-reported patient outcomes in chronic hemodialysis units. Nephrology Nursing Journal, 35(2), 123-145.

Vincent, C., Taylor-Adams, S., \& Stanhope, N. (1998). Framework for analysing risk and safety in clinical medicine. BMJ: British Medical Journal, 316(7138), 1154.

Wright, K. (2010). Do calculation errors by nurses cause medication errors in clinical practice? A literature review. Nurse education today, 30(1), 85-97.

Zhang, J., Patel, V. L., \& Johnson, T. R. (2002). Medical error: Is the solution medical or cognitive? Journal of the American Medical Informatics Association, 9(Suppl 6), S75-S77. 